\title{
TREATMENT OF INTERNAL THORACIC ARTERY STEAL SYNDROME WITH SUPRACLAVICULAR APPROACH
}

\author{
P. K. Spanos, MD, A. D. Bisbos, MD, and I. I. Arditis, MD, Thessaloniki, Greece
}

The routine use of internal thoracic artery (ITA) has simplified its harvesting technique, but there are still circumstances in which it is difficult to ligate the major branches. It would be great help if the ITA were included in preoperative cardiac catheterizations.

Postoperative steal syndrome may occur because of a large patent branch of the ITA, alone or in conjunction with high coronary vascular resistance. The diagnosis is a combination of the clinical picture, a positive stress test result, and the selective ITA angiogram. ${ }^{1}$ The condition is dealt with either in the catheterization lab with embolization of the ITA branch or in the operating room with surgical ligation of the branch (with a medial resternotomy, a lateral thoracotomy, a lateral parasternal intercostal incision, or a left supraclavicular incision). The occlusion of the branch with microcoil embolization is

From the Department of Cardiac Surgery, St. Luke's Hospital, Thessaloniki, Greece.

Received for publication June 16, 1997; accepted for publication June 30, 1997.

Address for reprints: A. D. Bisbos, MD, A. Nastou 12 Str., Thessaloniki 542 48, Greece.

J Thorac Cardiovasc Surg 1998;115:464-5

Copyright (C) 1998 by Mosby, Inc.

$0022-5223 / 98 \$ 5.00+0 \quad \mathbf{1 2 / 5 4 / 8 4 4 3 9}$ easy and essentially quick, but it requires the correct equipment. The procedure is at times only partially successful, and there are cases in which recanalization has occurred. $^{2,3}$

The medial resternotomy is tedious because of adhesions; there is a danger of injuring the ITA, and, if the branch is located extremely proximally, it is difficult to ligate. ${ }^{1}$ A left lateral thoracotomy is relatively easy but has the disadvantage of one more large incision, possible postoperative complications, and delayed recovery. A left parasternal intercostal incision has the advantage of a small incision, but the operative field is limited and there are adhesions. Finally, there is the possibility of surgical ligation with the left supraclavicular incision. With this approach, we have been able to ligate the branch safely, quickly (mean operative time 15 to 20 minutes), and with no adhesions and minimal repercussions for the patient. This is the best method for branches that are located extremely proximally.

We have dealt with three cases of ITA steal syndrome. These three patients had early postoperative angina (2 to 8 months after the operation) and a positive thallium 201 stress test result. Two patients had hypertrophic myocardium, and the third had a history of an old anterior myocardial infarction. Cardiac angiography revealed patent vein grafts. The left ITA was also patent, with a large side branch that originated 1 to $4 \mathrm{~cm}$ distal to the 
beginning of the left ITA. There was a decrease in the diameter of the ITA peripherally from the beginning of the branch (Fig. 1).

Surgery. The procedure was done with endotracheal anesthesia. A supraclavicular incision about 5 to $6 \mathrm{~cm}$ in length was made parallel and about 1 to $2 \mathrm{~cm}$ above the clavicle. A temporary transection of the clavicular head of the sternocleidomastoid muscle was needed. During dissection of the structures, caution was exercised to avoid injury of the nerves (phrenic or vagus), great thoracic duct, or ITA. After the exposure of the subclavian artery and ITA takeoff, the ITA was prepared peripherally until the branch was identified. The branch was then ligated with two clips and the incision was closed layer by layer. No drainage was needed.

Spasm of the ITA was not observed. The postoperative courses of these three patients were uneventful, and they were discharged the day after the operation. They were screened by catheterization to ascertain that the ligation of the branch was intact. Their angina had disappeared, and their stress test results were negative. The patients were free of symptoms at 2 years after the operation.

Discussion. The flow of the ITA is influenced by blood pressure and resistance of the coronary vascular network. Some surgeons do not dissect the ITA proximally and medially to the thymus gland, but this may leave a large pericardial or thymic branch unligated. Some authors have noted that if the subclavian artery does not have significant stenosis and the coronary vascular network is intact, then the unligated branches will not cause ischemia and will not influence the patency of ITA. ${ }^{4}$ Others have reported a significant decrease in the diameter of the ITA peripherally to the origin of the large branch. ${ }^{5}$ Seki and colleagues ${ }^{6}$ noted that patients with ITA string sign had no postoperative angina pectoris clinically or during a controlled check with thallium 201. They observed a decrease in the diameter of the ITA peripheral to the branch, but the width of the lumen (about $2 \mathrm{~mm}$ ) was sufficient for the perfusion of the left anterior descending coronary artery. They speculated that the postoperative diameter of the ITA is associated with the degree of stenosis and flow of the coronary vessel.

We believe that if coronary vascular resistance is high (bad vascular bed, hypertrophic myocardium) or the coronary vessel has no critical stenosis $(>70 \%)$ and there is a highly patent branch ( $>30 \%$ of the diameter of the ITA), it is possible for the steal phenomenon and angina pectoris to occur. The left supraclavicular incision offers immediate, complete, and relatively safe treatment for the patient with postoperative angina pectoris caused by a steal from a high unligated ITA branch. It has little negative effect on the general well-being of the patient.

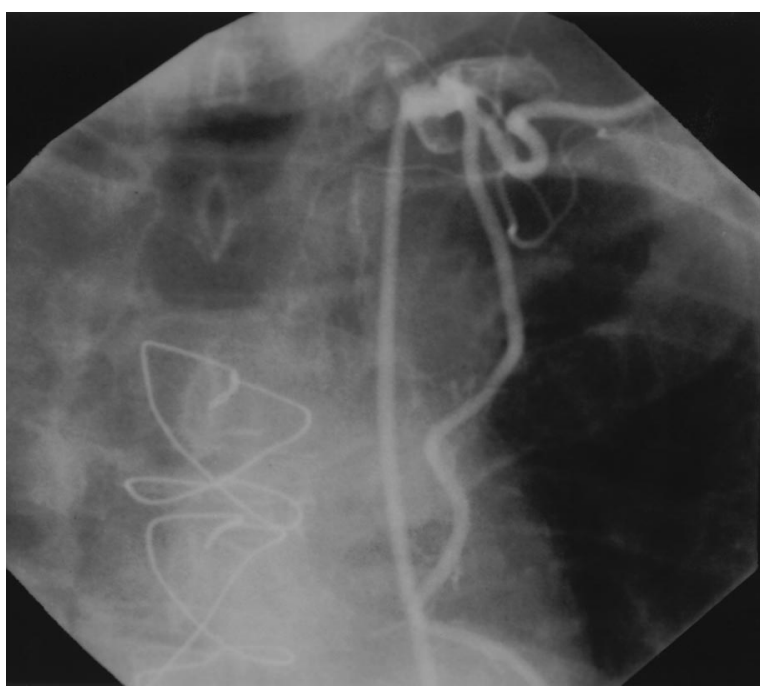

Fig. 1. Cardiac angiogram in patient with history of anterior myocardial infarction reveals patent vein grafts and left ITA. Note a large side branch, which was producing steal syndrome.

The actual surgical time required is minimal ( $\leq 20 \mathrm{~min}$ utes), and the results are immediate. The patients can be discharged from the hospital the next day.

\section{REFERENCES}

1. Pelias A, Del Rossi A. A case of postoperative internal mammary steal. J Thorac Cardiovasc Surg 1985;90:794-6.

2. Mishekel G, Willinsky R. Combined PTCA and microcoil embolization of a left internal mammary artery graft. Cathet Cardiovasc Diagn 1992;27:141-6.

3. Sbarouni E, Corr L, Fenech A. Microcoil embolization of large intercostal branches of internal mammary artery grafts. Cathet Cardiovasc Diagn 1994;31:334-6.

4. Ivert T, Huttunen K, Landou C, Bjork V. Angiographic studies of internal mammary artery grafts 11 years after coronary artery bypass grafting. J Thorac Cardiovasc Surg 1988;96:1-12.

5. Singh R, Sosa J. Internal mammary artery coronary artery anastomosis: influence of the side branches on surgical result. J Thorac Caardiovasc Surg 1981;82:909-14.

6. Seki T, Kitamura S, Kawachi K, et al. A quantitative study of postoperative luminal narrowing of the internal thoracic artery graft in coronary artery bypass grafting. J Thorac Cardiovasc Surg 1992;104:1532-8. 